\title{
Convulsions in early post-partum period, a diagnostic dilemma
}

\author{
Anil H. Inamdar ${ }^{1}$, Saunitra A. Inamdar ${ }^{2}$, Vaidehi S. Subhedar ${ }^{2, *}$ \\ ${ }^{1}$ Department of Medicine, JNMC, Sawangi (M), Wardha, Maharashtra, India \\ ${ }^{2}$ Department of Obstetrics and Gynaecology, JNMC, Sawangi (M), Wardha, Maharashtra, India
}

Received: 9 March 2013

Accepted: 22 March 2013

\section{*Correspondence:}

Dr. Vaidehi S. Subhedar,

E-mail: vaidehisubhedar@gmail.com

(C) 2013 Inamdar AH et al. This is an open-access article distributed under the terms of the Creative Commons Attribution License, which permits unrestricted use, distribution, and reproduction in any medium, provided the original work is properly cited.

\begin{abstract}
Neurocysticercosis is the most common helminthic (tapeworm) infection of the brain worldwide. It presents as hydrocephalus and acute onset seizures. A 28-year-old para 3 live 3 [P3L3], post-partum [day 7], resident of Arvi, presented in casualty during emergency hours with headache and fever since 7 days. She presented with h/o convulsions 2 episodes, one on day 5 and one on day 7 of her full term vaginal home delivery. She presented to the Emergency Department on day 7 with generalised tonic-clonic seizures preceded by nausea and headache. All her blood investigations were within normal limits except an extremely surprising finding on CT scan. $40 \%$ of patients having postpartum convulsions do not experience preeclampsia, clinical awareness is essential for early treatment and care.
\end{abstract}

Keywords: Post- partum convulsions, Neurocysticercosis, Emergency

\section{INTRODUCTION}

Pregnant women may present with abnormal symptoms that are assumed to be related to the pregnancy. ${ }^{1}$ When a pregnant or newly postpartum woman has seizures, eclampsia may be the most likely diagnosis, but it may not be accurate. There are a number of causes of seizures in the post-partum period such as eclampsia, cerebral venous thrombosis, meningitis, encephalitis, tuberculoma, neurocysticercosis etc. There may also be considerable overlap in the presentation of these conditions, making diagnosis and treatment difficult. ${ }^{2}$ Postpartum eclampsia is a rare, frightening, and potentially tragic complication of hypertensive pregnancies, usually developing within 48 hours of delivery. Seizures occurring days to weeks after parturition are exceedingly uncommon and require rapid, precise clinical evaluation by multiple specialists. $^{3}$

\section{CASE REPORT}

A 28-year-old para 3 live 3 [P3L3], post-partum [day 7], resident of Arvi, presented in casualty during emergency hours with headache and fever since 7 days. She presented with h/o convulsions 2 episodes, one on day 5 and one on day 7 of her full-term vaginal home delivery. She presented to the Emergency Department on day 7 with generalised tonic-clonic seizures preceded by nausea and headache. There was history of similar seizures on day 5 of her delivery. There was history of raised temperature off and on since 7 days. . There was no history of tinnitus or neck rigidity, visual disturbances.

On examination, Glasgow Coma Scale (GCS) was 8/15 with normal peripheral neurological reflexes and equally reacting pupils. She was febrile with a temperature of $101^{\circ} \mathrm{F}$, pulse rate of 114 beats $/ \mathrm{min}$, blood pressure of 108/46 $\mathrm{mmHg}$ and $\mathrm{SPO}_{2}$ (oxygen saturation) of $98 \%$ on $5 \mathrm{~L} / \mathrm{min}$ oxygen. Chest and abdominal examination were normal. Obstetricians thought of it to be a case of post-partum eclampsia but since the patient had fever and she presented with seizures for the first 
time after 5 days of delivery, physician's advice was sought for. Routine investigations showed a haemoglobin of $10 \mathrm{~g} / \mathrm{dL}$, white cell count (WCC) of $15.9 \times 10^{9} / \mathrm{L}$, platelets of $102 \times 10^{9} / \mathrm{L}$, normal urea, electrolytes, clotting, liver function tests, uric acid and no proteinuria. A CT scan was advised. To our surprise it revealed a ring enhancing lesion diagnostic of neurocysticercosis.

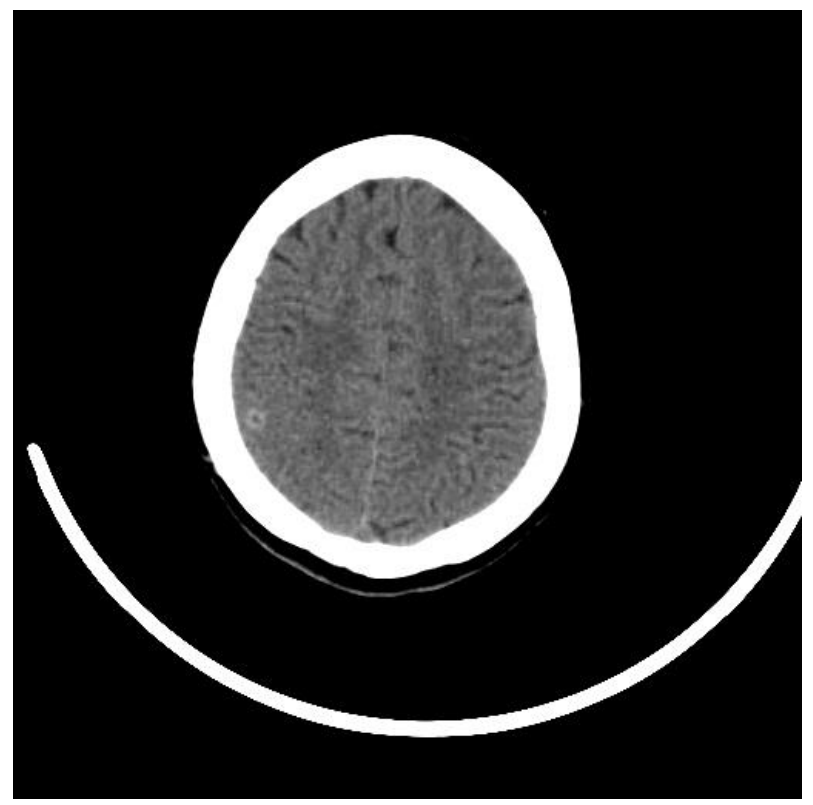

Figure 1: CT scan image.

Our patient was treated with inj phenytoin 100mg IV for 3 days later shifted to oral medication, Tab. Albendazole, Tab. Prednisolone.

\section{DISCUSSION}

Cysticercosis refers to tissue infection after exposure to eggs of Taenia solium, the pork tapeworm. The disease is spread via the fecal-oral route through contaminated food and water, and is primarily a food borne disease. After ingestion the eggs pass through the lumen of the intestine into the tissues and migrate preferentially to the brain and muscles. There they form cysts that can persist for years. In some cases the cysts will eventually cause an inflammatory reaction presenting as painful nodules in the muscles and seizures when the cysts are located in the brain. Symptomatic disease from Taenia solium cysts in the brain is referred to as neurocysticercosis and is the most common helminthic (tapeworm) infection of the brain worldwide. The life cycle involves humans as a definite host and pigs as an intermediate host. Pigs ingest contaminated food or water that contains eggs or proglottids from human feces. The eggs (ova) develop into cysticerci in pig muscles. Humans become infected when they ingest raw or undercooked pork that contain viable cysticerci. Upon reaching the small intestine, the scolex attaches to the intestinal wall and a proglottid chain grows. T. solium releases three to six proglottids/day, bearing 30,000 to 70,000 eggs per proglottid into the intestine. Nearly 250,000 ova are passed daily into the human feces and to the environment, and the cycle continues. ${ }^{4}$ Infections with cysticercus occur after humans consume the ova from exogenous sources or through self-infection via the fecaloral route. Humans, in this case, are intermediate hosts. Ova are digested in the stomach and release oncospheres which penetrate the intestinal wall and reach the bloodstream. ${ }^{5}$ These oncospheres develop into cysticerci in any organ but are common in brain, subcutaneous tissue, or eyes. The term neurocysticercosis is generally accepted to refer to cysts in the parenchyma of the brain. It presents with seizures and, less commonly, headaches. The diagnosis of neurocysticercosis is mainly clinical, based on a compatible presentation of symptoms and findings of imaging studies.

\section{Imaging}

Neuroimaging with CT or MRI is the most useful method of diagnosis. ${ }^{4}$ CT scan shows both calcified and uncalcified cysts, as well as distinguishing active and inactive cysts. Cystic lesions can show ring enhancement and focal enhancing lesions.

\section{Neurocysticercosis: Management}

Neurocysticercosis most often presents as hydrocephalus and acute onset seizures, thus the immediate mainstay of therapy is emergent reduction of intracranial pressure and anticonvulsant medications. Antiparasitic treatment should be given in combination with corticosteroids and anticonvulsants to reduce inflammation surrounding the cysts and lower the risk of seizures.

\section{CONCLUSION}

Many patients having postpartum convulsions do not experience preeclampsia, hence clinical awareness is essential for early treatment and care.

\section{Funding: None \\ Competing interests: None declared \\ Ethical approval: Not required}

\section{REFERENCES}

1. Mendelson SG. Maternal grand mal seizure leads to a surprising diagnosis of Dandy-Walker variant. J Obstet Gynecol Neonatal Nurs 2011;40:458-62.

2. Jamadarkhana S, Law RC. Seizures in the early postpartum period: A diagnostic dilemma. Indian $\mathbf{J}$ Anaesth 2012;56:183-5.

3. Felz MW, Barnes DB, Figueroa RE. Late postpartum eclampsia 16 days after delivery: case report with clinical, radiologic, and pathophysiologic correlations. J Am Board Fam Pract 2000;13:39-46. 
4. Davis LE. "Neurocysticercosis" Emerging Neurological Infections edited by Power, $\mathrm{C}$ and Johnson RT. Taylor \& Francis Group; 2005:261-87.

5. Centers for Disease Control and Prevention. "Cysticercosis." Available at http://www.cdc.gov/ncidod/dpd/parasites/cysticercos is/factsht_cysticercosis.htm. Accessed 19 January 2013.

DOI: $10.5455 / 2320-1770 . i j r \operatorname{cog} 20130627$

Cite this article as: Inamdar AH, Inamdar SA,

Subhedar VS. Convulsions in early post-partum

period, a diagnostic dilemma. Int J Reprod

Contracept Obstet Gynecol 2013;2:231-3. 